\section{Role of interaction between B cells and epithelial cells in pSS}

We read with great interest the recent publication by Rivière et al, concerning the activation of B cells by salivary gland epithelial cells (SGECs) from patients with primary Sjögren's syndrome (pSS). ${ }^{1}$ The authors elegantly show that coculture of CD19 ${ }^{+}$ peripheral blood B cells with SGECs isolated from labial salivary glands (LSGs) of patients with pSS increases expression of the $\mathrm{B}$ cell activation marker CD38, and the memory B cell marker CD27. This effect was the most noticeable with further stimulation of toll-like receptor 3 by means of Poly(I:C) medium supplementation. Treatment of cocultures with agents ablating specific B cell signalling pathways (ibrutinib, blocking BTK signalling), and non-B cell specific pathways (LY294002 blocking the PI3K pathway and leflunomide, inhibiting lymphocyte proliferation) reduced this effect somewhat.

We would like to take the opportunity to comment on these interesting findings. First, their main conclusion is that SGECs (by presumption ductal cells) from patients with pSS support the activation and survival of B cells. We would like to add that we have previously demonstrated in situ the presence of an epithelium-associated subset of B cells, expressing FcRL4, in both minor (labial) and major (parotid) SGs of patients with pSS. $^{2}$ This FcRL4 ${ }^{+}$B cell subset is highly proliferative, and located both periductally and intraductally. ${ }^{2}$ Follow-up studies by Verstappen et al using RNAseq revealed that parotid FcRL4 ${ }^{+}$ $\mathrm{B}$ cells in SGs express genes indicative of both chronic (T-bet, CD11c) and general (TACI, CXCR3, NF-kB signalling genes, IL-6) activation. ${ }^{3}$ We further provided some evidence that these chronically activated (intra-)epithelial B cells are involved in epithelial cell proliferation, resulting in the formation of lymphoepithelial lesions (LELs). ${ }^{2-4}$ The findings of Rivière et al support our notion of an intimate relationship between epithelium and B cells in SGs of patients with pSS, which might be very relevant for the pathogenesis of the disease. We would be extremely curious to see if in the studies of Rivière et al, FcRL4 is also differentially expressed in B cells sorted from LSGs of patients with pSS.

Second, Rivière et al employed cocultures of bulk (bloodderived) $\mathrm{CD} 19^{+} \mathrm{B}$ cells with SGECs. We suggest that the unrefined use of the CD $19^{+}$pool makes the interpretation of which $\mathrm{B}$ cell population, for example CD27 ${ }^{-}$and $\mathrm{CD} 27^{+}$naive and memory B cells, respectively, or FcRL4 ${ }^{+} \mathrm{B}$ cells, proliferates (or dies) following SGEC coculture challenging to gauge. Additionally, the accurate recapitulation of pSS-associated B cell/ SGEC dynamics in this system can be questioned, considering the lack of crucial B cell stimuli to fully mimic complete B cell activation (TLR7 and/or TLR9 agonism, presence of IL-21 and BCR stimulation). In the same trend, the application of potential therapeutic agents (eg, LY294002 blocking the PI3K pathway) and stimuli (IFN- $\alpha$, IFN- $\gamma$ and Poly(I:C)) to B cellSGEC cocultures and read out via $B$ cell viability render the data challenging to interpret in terms of effects on the epithelium. Considering the likely crosstalk between the two cellular entities, we wonder whether the authors plan to probe this in future experiments.

Finally, regarding the study of SGECs alone, the authors employed CD326 (EpCAM) to select epithelial cells from digested LSGs. Transcriptomics analysis of these $\mathrm{CD} 326^{+}$cells was performed. We were surprised to see expression of immune genes such as IGHG1, BTK (B cell/monocyte restricted), CD $8 A$ (NK/T cell restricted) in the CD $326^{+}$SGEC fraction, and were wondering how the authors interpret these findings (Table S3). The lack of pathways reflecting changes in epithelial cell dynamics (cell cycle, proliferation, apoptosis) may also suggest that this SGEC system do not truly mirror the in vivo situation suggested by other authors. ${ }^{5-9}$ The inference from the paper is that $\mathrm{CD} 326^{+}$cells equate to ductal cells in the LSG, or least no indication to the contrary is stated. Acinar cells, epithelial cells present in LSGs, also express CD326 (figure 1). Considering their likely involvement in pSS pathogenesis, acinar cells may be partly responsible for the immune profile observed. ${ }^{10-13}$ Using SGECs might well be an oversimplification of the SG, and
A

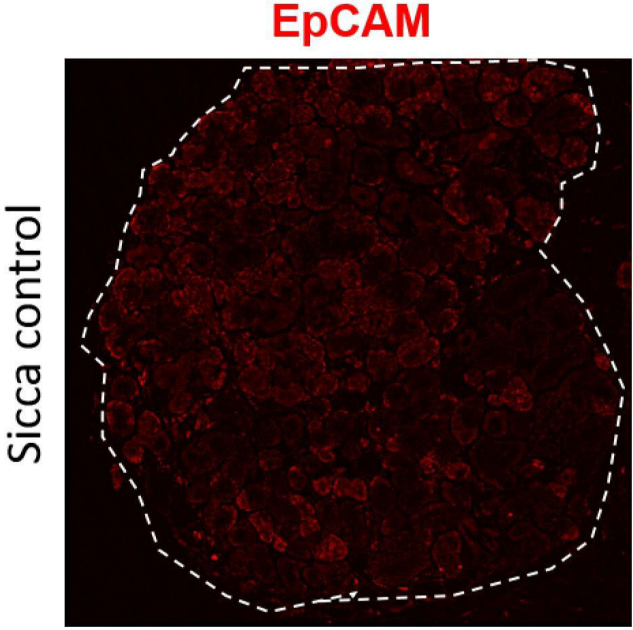

B

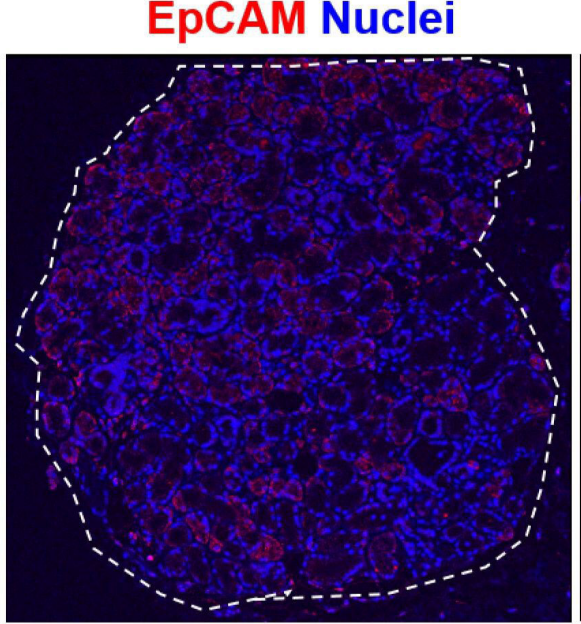

C

\section{EpCAM Nuclei}

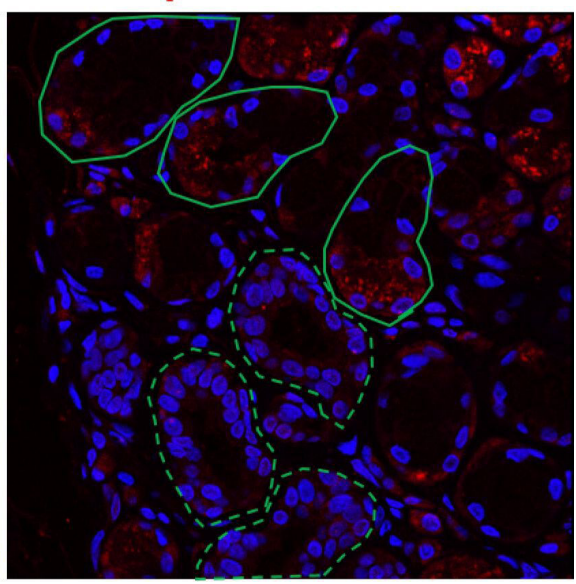

Figure 1 Both ductal and acinar epithelial cells express CD326 (EpCAM) in the LSGs. (A) EpCAM immunofluorescence staining of a sicca control LSG. (B) Merged EpCAM immunostaining with nuclear counterstain. (C) High-resolution microscopy of ductal cells (dashed green line) and acinar cells (solid green line), showing EpCMA expression by both. Methodology: paraffin sections of LSGs were dewaxed and rehydrated. Antigen retrieval was performed with a sodium citrate ( $\mathrm{pH}$ 6.0) buffer containing $0.5 \%$ Tween. Sections were blocked in $1 \%$ bovine serum albumin (BSA), and incubated overnight at $4^{\circ} \mathrm{C}$ in mouse anti-human EpCAM conjugated to the fluorophore e660, at 1:100 dilution (eBioscience clone 1B7). Nuclei were counterstained with Hoechst and confocal microscopy performed with the Leica TCS Sp8 confocal microscope. LSG, labial salivary gland. 
whether cultured SGECs are representative of in situ epithelial cells remains to be shown.

Although providing a platform for drug screening from which to further expand on and certainly representing an important contribution to the field, the applicability of two-dimensional epithelial cultures to in situ SG architecture remains to be validated. Three-dimensional approaches using SG organoids may represent a step towards true reflection of reality, and have been shown to provide valuable information about epithelial cell dynamics in pSS. ${ }^{6}$ While acknowledging the novel and extensive work presented by Rivière et al, we look forward to seeing how the more intricate interactions between $\mathrm{B}$ cells and the epithelium can be teased apart, including those of LEL development.

\section{Sarah Pringle • , Gwenny M Verstappen, Hendrika Bootsma,} Frans G M Kroese

Rheumatology and Clinical Immunology, University Medical Center Groningen, University of Groningen, Groningen, Netherlands

Correspondence to Dr Sarah Pringle, Rheumatology \& Clinical Immunology, University Medical Center Groningen, 9713 GZ Groningen, Netherlands; s.a.pringle@umcg.nl

Twitter Sarah Pringle @SjogrensUMCG; @springles82

Contributors SP, GMV and FGMK generated data, and formulated the manuscript first draft. HB read the manuscript critically.

Funding ReumaNederland (LLP-29, T015-052).

Competing interests None declared.

Patient and public involvement Patients and/or the public were not involved in the design, or conduct, or reporting or dissemination plans of this research.

Patient consent for publication Not required.

Provenance and peer review Not commissioned; internally peer reviewed.

(C) Author(s) (or their employer(s)) 2020. No commercial re-use. See rights and permissions. Published by BMJ.

\section{A) Check for updates}

To cite Pringle S, Verstappen GM, Bootsma H, et al. Ann Rheum Dis Epub ahead of print: [please include Day Month Year]. doi:10.1136/annrheumdis-2020-219079

Received 8 September 2020
Accepted 9 September 2020

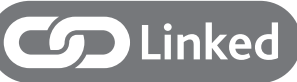

- http://dx.doi.org/10.1136/annrheumdis-2020-219096

Ann Rheum Dis 2020;0:1-2. doi:10.1136/annrheumdis-2020-219079

ORCID iD

Sarah Pringle http://orcid.org/0000-0002-0779-1680

\section{REFERENCES}

1 Rivière E, Pascaud J, Tchitchek N, et al. Salivary gland epithelial cells from patients with Sjögren's syndrome induce B-lymphocyte survival and activation. Ann Rheum Dis 2020:annrheumdis-2019-216588.

2 Haacke EA, Bootsma H, Spijkervet FKL, et al. FCRL4 ${ }^{+}$B-cells in salivary glands of primary Sjögren's syndrome patients. J Autoimmun 2017;81:90-8.

3 Verstappen GM, Ice JA, Bootsma H, et al. Gene expression profiling of epitheliumassociated FCRL4+ $B$ cells in primary Sjögren's syndrome reveals a pathogenic signature. J Autoimmun 2020;109:102439.

4 van Ginkel MS, Haacke EA, Bootsma $\mathrm{H}$, et al. Presence of intraepithelial B-lymphocytes is associated with the formation of lymphoepithelial lesions in salivary glands of primary Sjögren's syndrome patients. Clin Exp Rheumatol 2019;118:42-8.

5 Wang $X$, Shaalan A, Liefers $S$, et al. Dysregulation of NF-kB in glandular epithelial cells results in Sjögren's-like features. PLoS One 2018;13:e0200212.

6 Pringle S, Wang X, Verstappen GMPJ, et al. Salivary gland stem cells age prematurely in primary Sjögren's syndrome. Arthritis Rheumatol 2019;71:133-42.

7 Vakrakou AG, Boiu S, Ziakas PD, et al. Systemic activation of NLRP3 inflammasome in patients with severe primary Sjögren's syndrome fueled by inflammagenic DNA accumulations. J Autoimmun 2018;91:23-33.

8 Manoussakis MN, Spachidou MP, Maratheftis Cl. Salivary epithelial cells from Sjogren's syndrome patients are highly sensitive to anoikis induced by TLR-3 ligation. J Autoimmun 2010;35:212-8.

9 Manoussakis MN, Kapsogeorgou EK. The role of intrinsic epithelial activation in the pathogenesis of Sjögren's syndrome. J Autoimmun 2010;35:219-24.

10 Sung HH, Castro I, González S, et al. Muc1/Sec and MUC1/Y overexpression is associated with inflammation in Sjögren's syndrome. Oral Dis 2015;21:730-8.

11 Ewert P, Aguilera S, Alliende C, et al. Disruption of tight junction structure in salivary glands from Sjögren's syndrome patients is linked to proinflammatory cytokine exposure. Arthritis Rheum 2010;62:1280-9.

12 Castro I, Albornoz N, Aguilera S, et al. Aberrant MUC1 accumulation in salivary glands of Sjögren's syndrome patients is reversed by TUDCA in vitro. Rheumatology 2020;59:742-53.

13 Barrera M-J, Aguilera S, Veerman E, et al. Salivary mucins induce a Toll-like receptor 4-mediated pro-inflammatory response in human submandibular salivary cells: are mucins involved in Sjögren's syndrome? Rheumatology 2015;54:1518-27. 